\title{
XLI. Further thoughts on Mr. Herapath's demonstration
}

\section{T.S. Davies Esq.}

To cite this article: T.S. Davies Esq. (1825) XLI. Further thoughts on Mr. Herapath's demonstration, Philosophical Magazine Series 1, 66:330, 273-277, DOI:

10.1080/14786442508673964

To link to this article: http://dx.doi.org/10.1080/14786442508673964

册 Published online: 10 Aug 2009.

Submit your article to this journal $\sqsubset \pi$

Џ Article views: 2

Q View related articles $\asymp$ 
Mr. T. S. Davies on Mr. Herapath's Demonstration. 273

round the staff, it is out of the diagonal line in any other position, and of course throws both the diagonal and perpendicular out of their true directions.

In measuring diagonals, \&c. by means of the chain and common cross, Mr. Newton says, "The young practitioner frequently is obliged to prick his staff' in six or seven different places before he can succeed in finding the diagonal, \&c., but in using the above he will seldom find it requisite to ground his staff more than once, in order to answer the same purpose." Now it is evident this new instrument can be placed the first time only 18 inches, at most, nearer to the required point than the common cross (18 inches being the length of the revolving $\operatorname{arm} \mathrm{F} \mathrm{H}$ ). This distance on the diagonal on either side of the point where the true perpendicular falls, will cause a difference in the lengths of the perpendiculars, supposing them to be one, two, three, four, and five chains in length respectively, of $\frac{1}{5}, \frac{1}{10}, \frac{1}{15}, \frac{1}{20}$, and $\frac{1}{25}$ part of an inch only, in their respective lengths; and if a cross can be placed within the distance of 18 inches, on the first trial, of the true point where the perpendicular falls on the diagonal (as Mr. Newton says it is seldom requisite to ground his staff more than once), I really cannot see the necessity for pricking the staff in five or six different places afterwards. Errors, I may say, of almost infinitely greater magnitude arise from inattention to the correct length of the chain, and to the chain-leader not putting down his pins in a perpendicular direction, \&c.

The difference of 1-5th of an inch, or even of an inch or two, will make little or no difference in the result, as I believe it is not very usual for even professional surveyors to read off to the fraction of a link.

\section{Further Thoughts on Mr. Herapath's Demonstration. By T. S. Davirs, Esq.}

TO find an interpretation different from that upon which I had commented given to Mr. Herapath's demonstration did not at all surprise me, as I had for some time hesitated which construction to put upon it myself; and of the two aspects under which I conceived it may be considered, I chose that which to me appeared the most feasible, as that under which the author himself would have it viewed. By considering $1+2_{r}+3_{r}+\ldots$ and $1+2_{v}+3_{v}+\ldots$ as representations of the series just deduced for integer values, rather than as an arbitrary denotation of the development for fractional ones (when Vol. 66. No. 330. Oct. 1825. 
no such values of $v$ and $r$ had even been in the most distani manner suggested), was not only the most natural course, but seemed to be far the least objectionable mode of proceeding. It is true the title of the article led us at once to see the ultimate object of the inquiry; but it by no means intimated that in the stage at which we had arrived, a different class of values from that we had been previously considering was to be given to the indices. It is not usual to employ quantities in an elementary investigation with a new import, without expressly stating that the import of them is changed at that step, nor can a due regard to perspicuity be consistent with such an omission. Every one conversant with subjects of this nature must be aware how vaguely and imperfectly the mere title of a paragraph must necessarily define the character of the symbols which are introduccl into an investigation. It will be recollected that not the slightest intimation had been given that it was concerning the symbols $r$ and $v$ that the ultimate results were sought; and in reality, the passage quoted by P. Q. in support of those symbols having been introduced as fractions, appears quite as much like an extension of the signification which they had previously possessed,-if indeed that be the meaning which Mr. Herapath himself wished to convey by it.

However, it is a matter of little importance what construction the passage will bear, or even which is its most obvious interpretation; it is as little, perhaps, in reference to the principle for which I contend,-whether Mr. Herapath has failed in his nsual precision of expression, or whether through haste or misconception I have mis-stated his processes. It is sufficient, in the present case, if when the most favourable statement of both views is made, that my principle equally applies, and that the cxample which I have selected of its application is equally pertinent, whichever interpretation of the selected process we may fix upon. If I can show that under the interpretation of P. Q. the demonstration is even more fauliy thin that I had already considered, then I think a step will be gained in the application of a great and pervading principle,-of a principle in itself so obvious, that $I$ am astonished it was not adopted when cxperiment was made the basis of mental disquisition, even though it had cscaped notice when Natural Philosophy was first placed upon the same foundation: and still more surprised am I to find that it is not unhesitatingly admitted amongst our very axioms in this talented and inquiring age. It is not a little remarkable that the only relics of the metaphysics of Pythagoras and Plato are to be found inwoven with the principles of that science which clains for 
itself the utmost degree of exactitude and certainty. Let us then divest the science of its artificial connexion with the mysticism of innate ideas and universal truths cognisable by us through other media than sensation and experience! When we can fairly understand the evidence upon which our knowledge actually rests, we shall have done much towards weeding its details of many deformities and irrelevant operations, and rendering not only the means of acquisition but those of discovery more facile than the most sanguine of us can at present form any notion of!

Let us consider, then,-if indeed the error be not too obvious to need remark at all,-the position laid down by $\mathrm{Mr}$. Herapath : when

$$
r+v=n=\text { indeterminate integer, }
$$

that $r$ and $v$ " will in point of value be independent." I take for granted here, that the distinctions in "value" here refer to integer or fractional values of the symbols; it is the only interpretation of which I can perceive the application in the present inquiry. Surely then $r$ and $v$ are mutually dependent: if not, the equation $r+v=$ integer is destroyed. Mr. Herapath's conditional equation and his conclusion cannot therefore simultaneously exist; and of course the reasoning which is built upon that simultaneous existence must also be subverted by this consideration. Indeed the "independence of the functions" $r$ and $v$ is just of the same character as would be the assumption of independence of an angle and its complement, or of a number and its reciprocal : and a demonstration built upon assumptions like these would be equally as valid as Mr. Herapath's demonstration of the binomial.

Mr. Herapath proceeds-" And because in the two right hand members of this" (an equation derived solely from his demonstration for integer values and the principles of combinations, in conjunction with $n=r+v$ ), "6 $r$ and $v$ are independent variables, these members when duly reduced must not contain any product of the powers of the variables; for if they did, the function of either variable would be affected by the changes of the other variable, wHICH IT sHovLD Noт." 'Will not then a variation take place in any specific function of a fraction and its complement, by changing the values of one of these? It is incumbent, at all events, on Mr. Herapath to show the truth of such a principle, before we can admit its application here $-\mathbf{a}$ task which when accomplished will introduce a new species of " mathematical magic," more refined, and not less ludicrous, than that upon which Berkeley and Maseres exercised their castigating irony. 
276 Mr. T. S. Davies on Mr. Herapath's Demonstration.

It is for the reason above given that we are to admit the identity of these two equations: (Phil. Mag. vol. lxv. p. 324.)

$\frac{(r+v)^{q-1}+a(r+v)^{q-2}+a}{1.2 \cdots(r+v)^{q-3}+\ldots}=q_{r}+2_{v}(q-1)_{r}+\ldots . q_{v}$,

and

$\frac{\left(r^{q-1}+v^{q-1}\right)+a\left(r^{q-q}+v^{q-2}\right)+\cdots \cdots}{1.2 \cdots(q-1)}=q_{r}+q_{v}$.

And further, for the independence of $\mathrm{v}$ and $\mathrm{r}$, we are to admit, that " this equation evidently gives

$$
q_{r}=r \cdot \frac{(r-1)(r-2)(r-3) \ldots}{1.2 \cdots(q-1)} \text { and } q_{v}=v \frac{(v-1)(v-2) \ldots}{1.2 \ldots(q-1)}
$$

rohich completes the proof."-(Ibid.)

As this latter conclusion is derived by taking $v$ and $r$ sepan rately equal to zero, a momentary recurrence to the original equation of condition $(r+v=$ integer) would have convinced Mr. Herapath that if every preceding step had been perfectly legitimate, still these resulting equations are not for fractional values of $\mathrm{r}$ and $\mathrm{v}$, but for integer only: and $\mathrm{I}$ am confident that that gentleman will see the force of this suggestion, and withdraw his claims to having given the "most complete and general demonstration which has yet been published of this celebrated theorem." His demonstration I confess is as good, but not better, than any other that has been given: and more, it is as good as any that ever will be, or that ever can be given.

It is now sufficiently clear, that in either view of Mr. Herapath's demonstration the same fallacy is involved,-the same gratuitous assumption employed; viz. an extension of the values of $r$ and $v$ to forms not consistent with the conditions originally stated as the basis of the investigation.

I hope I shall not be charged, even by implication, with any wish to do injustice to the mathematical labours of $\mathrm{Mr}$. Herapath. No man can entertain for that gentleman's indefatigable spirit and splendid powers of intellect a more sincere respect than 1 have ever done. The mistake of $\mathrm{Mr}$. Herapath is a very general one, -it originates in a principle which has obtained universal credit, - and is so far from involving anything derogatory from his mathematical character, that it is almost invariably found amongst the writings of men of the very first order of scientific merit.-This remark would have been unnecessary, had not P. Q. insinuated that my wish was "to overwhelm in the ruins of the binomial demonstration" 
the labours and discoveries of Mr. Herapath " in other parts of his writings." Nothing could be further from the truth than such a charge. The majority of Mr. H.'s writings have not been upon subjects in which the demonstration of the binomial, or even the truth of the binomial, is at all concerned. I have objected to a very small number of his methods of demonstration, but have not in a solitary instance objected to a single mathematical fact to which he lays claim. As well might P. Q. charge me with denying the truth of the binomial theorem, as with involving in the ruins of a single demonstration most of the labours of Mr. Herapath's life !

Bristol, Oct. 12, 1825.

Erratum.-In line 14 of my former paper (p. 115), for "that perfect one of all," read " that most perfect one of all."

XLII. Correction in Dr. UnE's Paper on the latent Heat of Vapours. By T. Tredgold, Esq.

Sir,

To Richard Taylor, Esq. \&c.

N Dr. Ure's paper on the latent heat of vapours in the Philosophical Transactions for 1818 (see Phil. Mag. vol. liii. p. 193) a considerable error in the mode of calculating the results of the experiments has not been noticed. When it is corrected, we have for the latent heat of steam, $888^{\circ}$ instead of $967^{\circ}$, for that of alcohol $355.1^{\circ}$ instead of $442^{\circ}$, \&c. The error occurs in the second operation. "From $42 \cdot 5^{\circ}$ to $212^{\circ}$ there are $169^{\circ} 5^{\circ}$; one half of which $=84.75^{\circ}$, or in round numbers $84^{\circ}$, is the rise of temperature which would be produced by adding to water at $4.2 \cdot 5^{\circ}$ its own weight of boiling water ; and $\frac{84}{161.7}=0.52 \cdot$ is the elevation which 200 grs. would occasion on 32340 grains." But the 200 grains has been added to 200 grs. to reduce its temperature to $84^{\circ}$ of excess : hence, either this reduction should not have been made, or 84. should be divided by $\frac{325}{4} 500=80.85$ instead of 161.7 .

Calculating by the formula for mixed fluids (Playfair's Nat. Phil. vol.i. art.317) we have $888.05=$ the latent heat of steam, when we suppose, as Dr. Ure has done, that there is no loss of heat in the operation, and that the specific heat of water is the same in the whole range of temperature from 42.5 to 212 .

Perhaps the notice of these errors in your Journal will lead to an investigation of this interesting subject.

I am, sir, your most obedient servant, 16, Grove Place, Lisson Grove, Oct, 18, 1825. Thomas Tredgold. 